\title{
LA CONCESION EN EL REGIMEN DE UTILIZACION DE LOS BIENES DE DOMINIO PUBLICO DE LAS CORPORACIONES LOCALES
}

$352.711: 336.115(46)$

\author{
por \\ José Luis Sánchez Díaz \\ Secretario de primera categoría de Administración local
}

SUMARIO: I. LA CONCESION Y LAS DISTINTAS FORMAS DE UTILIZACION DE LOS BIENES DEMANIALES: 1. Uso COMÚN: A) Relación entre uso común y uso especial: a) Análisis del artículo 61, 1, del Reglamento de Bienes. Usos comunes especiales sujetos a licencia. Limitaciones policiales al uso común. b) Estudio crítico del artículo 61, 2, del Reglamento de Bienes. Usos sometidos al régimen de autorización discrecional. B) Usos comunes y situaciones de colindancia. 2. Uso PRIVATIVO. Significado Y ALCANCE. 3. La DUALIDAD DE RÉGIMEN EN LA CONCESIÓN DEMANIAL.-II. CONCLUSIONES.

I. LA CONCESION Y LAS DISTINTAS FORMAS DE UTILIZACION DE LOS BIENES DEMANIALES

La figura de la concesión demanial gira en nuestro vigente Reglamento de Bienes en base a las formas de utilización del dominio público. El legislador ha montado el esquema conceptual clásico de la autorización y la concesión en torno a los distintos modos en que el dominio público puede ser utilizado por el ciudadano. De esta forma han venido a coincidir dos temas cuya dificultad y falta de precisión se observa tanto en el orden doctrinal como en el de su aplicación por los Tribunales. Como ha señalado García-Trevi- 
JANO (1), la distinción entre concesión y autorización en base a que aquélla crea un derecho ex novo en la esfera del administrado, mientras que la autorización remueve los obstáculos que se oponen al libre ejercicio de un derecho que ya existe en aquél, examinada detenidamente ofrece serias dudas para adoptarla con caracteres dogmáticos. Frente a potestades discrecionales de la Administración no es posible plantear la existencia de derechos subjetivos en los particulares. De ahí que el concepto clásico de autorización se bifurque en distintas categorías que ponen de relieve las posibles situaciones en que puede encontrarse el ciudadano frente al poder público (2).

Desde esta perspectiva vamos a intentar un análisis crítico de la normativa vigente en el Reglamento de Bienes, al objeto de precisar el encuadramiento que la concesión tiene entre las distintas formas de utilización de los bienes de dominio público.

\section{Uso ComúN}

Al hilo de dos cuestiones fundamentales se expone la teoría del uso común:

Examinar si el denominado uso especial, pese a los preceptos establecidos, debe ser considerado como una especie de uso común o concurrente, y distinguir el uso común de aquellas utilizaciones derivadas de una situación de colindancia con la vía pública.

\section{A) Relación entre uso común y uso especial.}

Bajo la rúbrica de uso común se entiende aquel que presente las siguientes características:

- Generalidad e igualdad. Corresponde indistintamente a cualquier ciudadano.

(1) "Autorizaciones y concesiones en el dominio marítimo». Revista Española de Derecho Maritimo, julio-septiembre 1963.

(2) J. A. MANZANEDo, Curso de Derecho administrativo económico, Instituto de Estudios de Administración Local, Madrid, 1970, distingue entre:

a) Constataciones regladas que se vinculan a la existencia de derechos subjetivos en los administrados.

b) Autorizaciones discrecionales, que suponen meros intereses o expectativas en los particulares.

c) Autorizaciones operativas con interesamiento constante de la Administración en la actividad que se lleva a efecto. 
- Libertad de ejercicio.

- Concurrencia. El uso común no excluye o limita la posibilidad de que otros ciudadanos compartan la utilización del bien.

Estas notas, que claramente se deducen de los artículos 59,60 y 61, 1, del Reglamento de Bienes, no están conformes, sin embargo, con lo establecido en el párrafo segundo del último precepto citado, que textualmente dice:

"Las autorizaciones se otorgarán directamente, salvo si, por cualquier circunstancia, se limitare el número de las mismas, en cuyo caso lo será por licitación, y si no fuere posible, porque todos los autorizados hubieren de reunir las mismas condiciones, mediante sorteo".

Como se puede apreciar, la nota de concurrencia que se predica del uso común se halla en contradicción con el carácter limitativo que se atribuye a las autorizaciones a que hace referencia el precepto citado. Si el uso común se define como aquel que no impide el que llevan a efecto los demás ciudadanos y su ejercicio constituye un derecho que sólo en determinados casos puede estar sujeto a un control policial de acuerdo con el ordenamiento jurídico, no se puede comprender cómo el párrafo segundo del artículo 61, al hablar del uso común especial, se está refiriendo a autorizaciones que pueden tener un carácter limitativo y por tanto excluyente. Una sola explicación encontramos a la cuestión planteada, y es que el artículo 61 contempla dos supuestos distintos. Primero, el de la autorización reglada en la que la Administración se limita a constatar o comprobar que el uso se ajusta a la naturaleza del domiminio, a los actos de su afectación y apertura al uso público y a los preceptos de carácter general, y segundo, el de la autorización discrecional que se aplica a los usos cuya autorización presenta un carácter limitativo, encuadrables, por tanto, dentro de la genérica denominación de usos privativos, pues éstos, según el artículo 59, 2, se refieren no sólo a los que excluyen la utilización del dominio público por los demás interesados, sino, además, los que la limitan.

a) Análisis del artículo 61, 1, del Reglamento de Bienes. Usos comunes especiales sujetos a licencia. Limitaciones policiales al uso común.

Como ha quedado apuntado, el uso común o concurrente, que 
se puede ejercer libremente por cualquier ciudadano, constituye una manifestación concreta de los derechos fundamentales de libertad e igualdad reconocidos en los apartados 1 y 3 del Fuero de los Españoles de 17 de julio de 1945, y sólo puede ser limitado conforme a un orden jerárquico de normas preestablecidas.

La actividad de la Administración tiene, pues, en estos supuestos un carácter reglado, y puede responder a una de estas tres motivaciones:

- Policía de conservación del bien.

- Policía de afectación del bien.

- Policía de orden público.

\section{a') Policía de conservación del bien.}

Trata de evitar los perjuicios materiales que puedan sufrir los bienes de dominio público con la consiguiente depreciación. Corresponde ejercerla al ente titular del bien. Un ejemplo característico lo constituyen todas aquellas medidas que tratan en la vía pública de mantener su conservación (evitando el tráfico pesado, haciendo que los medios mecánicos que circulan por las mismas vayarı en debidas condiciones, etc.) (3).

Incluso en virtud de estas facultades el ente titular se encuentra facultado para exigir determinadas exacciones que compensen los especiales gastos de conservación.

El Reglamento de Bienes, cuando se refiere al uso común especial indica que éste puede estar motivado por determinadas circunstancias que supongan una mayor intensidad en el uso o cualesquiera otras semejantes (art. $59,1 .^{\circ} \mathrm{b}$ ).

b') Policía de la afectación del bien.

En estos casos la Administración actúa para conservar y garantizar el fin primordial a que el bien se encuentra adscrito de una manera expresa o tácita. A ella se refiere el artículo 61, 1, cuando dice que las licencias se ajustarán a «la naturaleza del dominio, a los actos de su afectación y apertura al uso público y a los preceptos de carácter general».

(3) Cfr. J. A. Garcfa-Trevijano, aTitularidad y afectación en el ordenamiento jurídico español», Revista de Administración Pública, núm. 29, y Vallina Velarde, Vias provinciales, págs. 304 y sigs. 
Desde esta perspectiva se hace evidente que el uso común debe, por imperativo de la Ley, ser siempre un uso normal; no caben utilizaciones que no se ajusten al destino del bien. Sobre este particular conviene anotar que su funcionalidad no es un concepto absoluto e inmutable, sino que está sujeta a variaciones en el tiempo y en el espacio. Las vías públicas, por ejemplo, cumplen un destino mucho más amplio y variado en las grandes ciudades (circulación, publicidad, servicios de vialidad, fines comerciales, etc.) que en las pequeñas, en donde se destacan utilizaciones que serían impensables o muy difíciles en aquéllas (actividades artesanas, mercados semanales, etc.) (4).

c') Policía de orden público.

Se ejerce por razón de la actividad que sobre el dominio se desarrolla, independientemente del fin al que se encuntra adscrito el bien de dominio público. En este sentido son las normas propias que regulan aquélla las que entran en juego para cada uno de los aspectos a que se refiere: urbanísticos, de orden público, etc.

Estas limitaciones se presentan en un plano paralelo a la utilización del bien, pero sin confundirse con aquélla. Así la jurisprudencia ha señalado que «la autorización administrativa para ocupación de terrenos demaniales y la licencia municipal de policía de la edificación actúan en planos distintos y sucesivos...»(5). Este planteamiento se ve, no obstante, dificultado cuando las competencias sobre cada uno de estos aspectos se atribuyen a entidades públicas diferentes.

El Reglamento de Bienes alude al control establecido por la mayor peligrosidad del uso en el citado artículo $59,1 .^{\circ} \mathrm{b}$ ).

b) Estudio crítico del artículo 61, 2, del Reglamento de Bienes. Usos sometidos al régimen de autorización discrecional.

Hasta aquí nos hemos referido a aquellos supuestos en que el particular utiliza los bienes de dominio público de una manera concurrente $y$, por tanto, sin excluir la posibilidad de que otras personas puedan hacerlo.

(4) Garrido Falla, Tratado de Derecho administrativo, vol. II, págs. 465 y sigs.

(5) Nemesio RODRfGuez Moro, comentario a la sentencia citada, en REvisTa DB ESTUdIOS DE LA VIDA LOCAL, núm. 162, págs. 311 y sigs. 
Nos vamos a referir ahora al hecho de que el particular solicite autorización para utilizarlos, de modo que si se le otorgare puedan quedar excluidas terceras personas.

Lo primero que se aprecia en este supuesto es que esta utilización que el Reglamento de Bienes engloba bajo la fórmula genérica de uso común especial no es tal uso común por ser limitativa la autorización que faculta al particular para llevarlo a efecto. En consecuencia, no existe un derecho previo del particular a que aquélla le sea otorgada, sino simplemente a solicitar su uso, dadas las consecuencias que la utilización lleva consigo, pues excluye a otras personas a beneficiarse del mismo.

De aquí que GaRrido Falla (6), al estudiar las distintas formas de utilización de los bienes de dominio público, hable en este supuesto de uso especial y no de uso común especial, dado que las notas de discrecionalidad y precariedad que el referido autor atribuye a las autorizaciones de usos especiales no encajan en la teoría del uso común o concurrente.

En realidad, tales usos, en régimen de permiso que un sector doctrinal llama especiales, presentan esta característica más acentuada frente a los usos excluyentes, sometidos a régimen de concesión, que frente a los usos comunes. Las denominadas ocupaciones temporales o transitorias del dominio público que carecen de situación de fijeza constituyen, materialmente hablando, usos excluyentes del dominio público, aunque su régimen no sea el de la concesión, sino el de la simple autorización discrecional de carácter no constitutivo (7).

Sin embargo, como se puede observar, los distintos manuales de Derecho administrativo españoles han empleado el término uso

(6) Garrido Falla, Tratado..., vol. II, pág. 471.

(7) Así se ha reconocido en reiteradas sentencias del Tribunal Supremo (17 de mayo de 1932, 13 de noviembre de 1957, 27 de septiembre de 1965, 28 de julio de 1966 y 3 de marzo de 1967).

Por otra parte, la Dirección General de Registros, en reciente e interesantísima Resolución de 18 de abril de 1969, afronta el problema de la distinción entre permisos y concesiones en relación con la posible inscripción registral, señalando qúe «sólo pueden tener acceso al Registro aquellos actos administrativos que generan en favor del interesado un verdadero derecho real oponible a terceros y que vincula a la Administración durante un determinado plazo, pero no aquellas situaciones a precario o de mera tolerancia, que pueden cesar en cualquier momento sin derecho a indemnización por decisión unilateral de la entidad concesionaria, pues en estos supuestos el interesado no sólo no goza de un verdadero derecho real, sino que incluso no tiene a su favor derecho subjetivo alguno por total carencia de exigibilidad o vínculo obligatoriò. Véase B. B. Camy SánchezCaÑete, Comentarios a la Ley hipotecaria, edición 1971, C. E. H., tomo I, págs. 318 y 319. 
especial para referirlo a situaciones distintas en la utilización de los bienes de dominio público.

MARTINEZ USEROS y GARCIA OVIEDo lo consideran como una categoría del uso ordinario sometido a licencia y diferenciable del simple permiso. GaRRIDO FaLla, en cambio, lo identifica con el régimen de las autorizaciones discrecionales que no otorgan derechos al peticionario y que por tanto pueden ser revocadas sin indemnización alguna (8). Ello unido a la confusa sistematización de las autorizaciones en nuestro Reglamento de Bienes, puede explicąr la equívoca interpretación del uso especial.

\section{B) Usos comunes y situaciones de colindancia.}

Relacionado estrechamente con la teoría del uso común $\epsilon$ special se plantea el tema de las denominadas situaciones o derechos de los propietarios de inmuebles colindante con la vía pública. ¿Se han de incluir tales situaciones en la teoría del uso común especial? $¿$ Constituyen los denominados derechos de colindancia una manifestación más del que corresponde a todo ciudadano para utilizar libremente las vías públicas?

Si partimos de la idea de que derivadas de la propiedad urbana surgen para su titular derechos sobre el suelo que materialmente ocupa y derechos de colindancia, dentro de los límites que se establecen y perfilan en los planes de ordenación, es factible pensar que estas situaciones tienen un régimen muy específico que está estrechamente ligado a la normativa urbanística (9).

El particular puede utilizar la vía pública no sólo como cualquier ciudadano, sino también como titular de un haz de derechos que derivan de la situación del inmueble, del que es propietario, en relación con la vía pública, tales como el de acceso, luces y vistas, desagües, vuelos, etc. Desde esta perspectiva la licencia no solamente controla el ius aedificandi, sino además el derecho del colindante a utilizar la vía pública que subordina al interés de la comunidad y que adquiere plena vigencia una vez desafectada aquélla.

(8) Véase Garcfa Oviedo y MaRTfNez Useros, Derecho administrativo, vol. II, páginas 408 y sigs., que distinguen las formas de utilización en ordinarias y éstas en generales y especiales, y extraordinarias subdivididas por la forma de su otorgamiento en régimen de permiso o de concesión. Asimismo, Garrido Falla, Tratado..., vol. II, pág. 471.

(9) J. Gonźlez Pérez, Los planes de urbanismo, Publicaciones Abella, 1974, páginas 302 y sigs. 
El planteamiento de todas estas cuestiones excede en mucho el contenido del presente trabajo, por lo que un estudio más completo y detallado lo contienen las obras de P. Escribano CollaDo (10) y T. R. FERnández Rodríguez (11).

Aquí simplemente queremos precisar que estas situaciones de colindancia trascienden del concepto de uso común, dado que éste se atribuye por igual a todos los ciudadanos sin tener en cuenta la particular situación en que cada uno de ellos se encuentra, en tanto que estas utilizaciones específicas operan en relación a determinadas personas y responden al interés propio del particular colindante (12).

\section{Uso PRIVATIVo. Significado Y aLCANCE}

Aunque ya hemos aludido a él cuando se ha expuesto la teoría del uso especial, es preciso ampliar su estudio, tratando más detenidamente su problemática. El Reglamento de Bienes lo define como el constituido por la ocupación de una porción de dominio público, de modo que limite o excluya la utilización por los demás interesados (art. 59, 2).

En realidad, todo uso limitativo del que puedan llevar a efecto otras personas es en sí un uso excluyente.

La expresión uso privativo se opone al uso común y el concepto de uso excluyente al de uso concurrente. De ahí que si la nota de concurrencia se atribuye por disposición legal al uso común (se ejerce "de modo que el uso de unos no impide el de los demás interesados», artículo 57, 1, Reglamento de Bienes) en sentido contrario la nota de exclusión se puede predicar de los usos privativos. Cualquier limitación al uso concurrente participa de la naturaleza del uso privativo.

Nos queda por señalar el significado y alcance que podemos atribuir a este concepto. La legislación y jurisprudencia se han esforzado en distinguir el uso especial del uso privativo desde un punto de vista material. Para ello se han utilizado distintos criterios. Así la Ley de Puertos, en repetidos preceptos (artículos 38, 40,

(10) Las vias urbanas: concepto y régimen de uso, Madrid, 1973, págs. 437 y sigs.

(11) aLa situación de los colindantes con las vías públicas, Revista de Administración Pública, núm. 69, págs. 109 y sigs.

(12) Garcia DE ENTERRfa, aDictamen sobre oposición de un particular a la ocupación por otro de la calle con que linda el edificio del primeron, $R$. $D$. N., 1961, páginas 383 y sigs. 
41, 44 y 45), hizo objeto de concesión aquellas construcciones que tuviesen un carácter permanente; posteriormente la reciente Ley de Costas de 26 de abril de 1969 (artículo 10,3 en contraste con el articulo 17,3 ) señala como concesionables aquellas obras o instalaciones definidas por su fijeza. Desde nuestro punto de vista, tanto las instalaciones que ocupan la vía pública con carácter transitorio, como las que lo hacen sin instalaciones fijas, pueden constituir usos excluyentes, desde el punto de vista material. Ahora bien, no todo uso excluyente ha de quedar sometido al régimen concesional, habrá que distinguir entre aquellos cuyo otorgamiento puede ser revocado sin derecho a indemnización alguna, dadas las circunstancias de provisionalidad o transitoriedad con que fueron otorgados, de aquellos que tienen una situación de estabilidad y que en ocasiones suponen importantes desembolsos económicos. Los primeros serán objeto de permiso, y los segundos de concesión que sólo podrá ser revocada mediante la correspondiente indemnización (13).

Sobre este particular el criterio del Reglamento de Bienes no fue muy afortunado. Siguiendo una sistemática que respondía a una corriente legislativa y jurisprudencial muy en boga en el momento en que fue publicado, acoge en su seno la teoría de las concesiones a precario, admitiendo dentro del clausulado concesional la posibilidad de que la Corporación deje sin efecto la concesión antes del vencimiento del plazo, «sin resarcir los daños que se causaren, cuando la justificasen circunstancias sobrevenidas de interés público" (artículo 63, párrafo 10)(14). Contra este punto de vista un

(13) MARTfN Mateo, "La cláusula de precario en las concesiones de dominio público", Revista de Administración Pública, núm. 56, págs. 93 y sigs., distingue entre precariedad de primer grado, que se fundamenta en la alteración del elemento causal en los negocios jurídicos y que supone la posibilidad de revocación siempre que se indemnice al particular, y precariedad de segundo grado, que implica una mera tolerancia en situaciones transitorias conocidas previamente por el beneficiario y que pueden ser revocadas sin derecho alguno de aquél a percibir indemnización.

(14) En este sentido, Pérez Olea, aLa concesión de dominio público a título de precarion, en Revista de Administración Pública, núm. 24, 1957, pág. 188, apoyándose en el dictamen del Consejo de Estado de 14 de julio de 1948, sostiene la plena vigencia del Decreto de 10 de octubre de 1952, cuyo artículo $10^{\circ}$ establece que las autorizaciones para la ocupación de terrenos de dominio público para las líneas telefónicas se otorgarán siempre a título de precario, quedando obligada la Compañía Telefónica Nacional a realizar por su cuenta las modificaciones de las citadas líneas sin derecho a indemnización cuando lo exija el servicio público en general. En consecuencia, si bien el Decreto de 13 de mayo de 1954 vino a aceptar posteriormente que el traslado o modificación de líneas se haría costeando su importe por mitad entre la Compañía y la Administración pública, no descarta dicho autor la posibilidad de conceder en precario los bienes de dominio público. 
importante sector doctrinal [GarRido Falla (15), Leguina Villa (16) y Martín Mateo (17)] ha destacado la incompatibilidad de la cláusula' precarial, entendida como posibilidad revocatoria sin derecho a indemnización, con el régimen de la concesión.

Por otra parte, la legislación más avanzada se orienta por nuevos derroteros, estableciendo la prohibición de revocar determinadas autorizaciones o concesiones sin indemnizar a su titular. En este sentido el artículo 7 de la Ley de 18 de marzo de 1966 sobre expropiación forzosa y sanciones en materia de instalaciones eléctricas prevé que «la variación del tendido de una línea como consecuencia de proyectos o planes aprobados por la Administración en sus diversas esferas comportará el pago del coste de dicha variación $\mathrm{y}$ de los perjuicios ocasionados", en el mismo sentido que el artículo 29 del Reglamento de esta Ley, aprobado por Decreto 2.619/1966, de 20 de octubre.

Descartadas, pues, las concesiones a título de precario, ¿en qué precepto o preceptos del Reglamento de Bienes quedan encajados estos permisos?

A nuestro modo de ver, tal como ya se indicó anteriormente, el párrafo segundo del artículo 61 (a falta de una disposición clara y precisa, que de lege ferenda sería muy de desear, y que separara claramente el régimen de las autorizaciones regladas de las que tienen un carácter discrecional) cubre cualquier autorización que tuviera este carácter últimamente citado, dependiendo de cada caso en concreto y de las circunstancias que le rodearan el que se tratase de una simple autorización transitoria y por tanto revocable sin indemnización, o de una concesión con eficacia erga omnes y fuerza constitutiva.

\section{LA DUALIDAD DE RÉGIMEN EN LA CONCESIÓN DEMANIAL}

Convergentemente con lo expuesto, Guarta (18) estima que la concesión se define por razón de su contenido y que puede otorgarse a través de formas contractuales o unilaterales, pues cualquiera de ambas es idónea para aportar aquel contenido o concesión.

(15) Tratado de Derecho administrativo, vol. II, pág. 474, nota 76 .

(16) aInstalaciones de líneas eléctricas y precariedad administrativas, Revista. de Adminitración Pública, núm. 68.

(17) Véase nota 13.

(18) Derecho administrativo especial, Zaragoza, 1970, IV, pág. 344. 
En este sentido se estima que el régimen contractual resulta más apropiado para la concesión de servicios que para la demanial, en la que predomina su otorgamiento mediante acto unilateral constitutivo, y ello es así porque en la concesión de servicios la Administración está permanente y constantemente interesada en su prestación, pues ha de garantizar en todo momento su continuidad y la buena marcha del mismo, la cual queda mucho mejor garantizada por vía contractual que unilateral; en cambio, en la concesión demanial, una vez que ha sido otorgada, el interesamiento de la Administración sobre la actividad que se ejerce en el dominio ocupado se debilita e incluso desaparece si la ocupación se efectúa con el único fin de llevar a efecto unas simples obras e instalaciones. Tan sólo será aplicable el régimen contractual a la concesión demanial cuando ésta se otorgue subordinada a la de servicios, dada la fuerza absorbente del régimen del servicio público en nuestro vigente Reglamento de Bienes (artículo 58). Abundan en este criterio García Oviedo y Martinez Úseros (19), que señalan "que la concesión es también, como el permiso, una autorización que la Administración otorga a un particular para ocupar temporalmente un inmueble de dominio público con destino extraordinario, pero confiriendo un verdadero poder sobre la cosa». Se diferencia del permiso - siguiendo a MAYER - por su intensidad jurídica, ya que crea un derecho subjetivo que cristaliza en la atribución de un poder jurídico sobre el bien público (20). Asimismo, García dE ENTERRf́a y T. R. FERNÁNDEZ (21) consideran la concesión de dominio público como un acto administrativo necesitado de aceptación por el concesionario como condición de eficacia. Pero además nuestro Tribunal Supremo, en reciente e interesantísima sentencia de 23 de marzo de 1972 (Aranzadi 1.562), viene a confirmar el criterio expuesto cuando dice que:

"Que si bien las concesiones en general, y dentro de ellas las referentes al dominio público, ofrecen una cierta estructura contractual como consecuencia de su contenido sinalagmático, donde se insertan deberes y derechos recíprocos de concedente y concesionario, según parece sugerir el artículo 64 del Reglamento de Bienes de las Corporaciones locales al establecer en esta materia la supletoriedad

(19) Derecho administrativo, vol. II, pág. 412.

(20) Cfr. Genot, De l'utilisation privative de domaine public, Paris, 1928. AlvarezGendf, Dominio público, Barcelona, 1965, págs. 60 y sigs.

(21) Curso de Derecho administrativo, tomo I, Madrid, 1974, pág. 370. 
de las normas sobre contratación, resulta no obstante evidente, ante todo, que se trata de actos administrativos unilaterales necesitados para su perfeccionamiento de la aceptación posterior del destinatario, circunstancia común a muchos otros (nombramientos, etc.) y - además- que constituyen una categoría negocial individualizada en nuestro ordenamiento jurídico con un arraigo ya centenario, perfectamente delimitada respecto de otra también dotada de idéntica solera —el contrato administrativo- coincidente aquélla y éste en muchos aspectos sin que tales semejanzas impliquen identidad o conjunción, pues ambas instituciones aparecen sometidas a un régimen jurídico diferenciado en todas sus fases, desde el procedimiento de elaboración hasta los supuestos extintivos".

Justifica el criterio expuesto lo indicado por Villar Palasí (22) cuando dice, al tratar el tema de las concesiones administrativas, que «existe una diferencia profunda entre concesión de dominio y de servicios, dado que en la concesión de dominio el interés público es sólo reflejo, teniendo una pura eficacia interna como respondiendo al uti cives de la generalidad, en tanto que en la concesión de servicios la eficacia es extrospectiva frente al público, en quien se concreta uti singuli el interés de la prestación". La actitud de la Administración ha de ser, pues, distinta en la concesión de servicios y en la demanial, siendo en aquélla más activa y permanente a través de la vía contractual.

Sin embargo, como ha quedado señalado en la sentencia antes referida, nuestro vigente Reglamento de Bienes no responde en su totalidad al criterio que se señala. Si bien el artículo 61,2 permite, a nuestro modo de ver, otorgar concesiones por vía de acto administrativo unilateral, acto seguido en los artículos 62 y 64 parece prescribir para éstas el régimen contractual al hacer supletorias las normas del Reglamento de Contratación de las Corporaciones locales. Esta situación se entiende que debe ser interpretada considerando que el régimen contractual sólo es aplicable en aquellos supuestos en que el uso privativo de un bien de dominio público va unido a la concesión de un servicio público. En estos casos la Administración incorporará al contenido de la concesión del servicio aquellas cláusulas que se refieran al uso del dominio, pero subordinando la concesión del dominio a la del servicio público (artículo 58,3 del Reglamento de Bienes).

(22) Villar Palasí, Voz «Concesiones administrativas», Nueva Enciclopedia Juridica, Scix, pág. 701 . 
Sobre este particular, Albi (23), al referirse al tratamiento que la denominada concesión de usos demaniales tiene en nuestro derecho positivo señala lo siguiente:

«El artículo 62 del Reglamento de Bienes considera concesiones de esta clase todas aquellas que entrañan el uso privativo y anormal de bienes de dominio público. El Reglamento de Servicios, por su parte (artículo 1, núm. 4 , en relación con el $9,7 .^{\circ} \mathrm{b}$ ), las califica de simples licencias. Habrá que ajustarse a este último criterio: en primer lugar porque es el de la disposición más reciente, y además porque el propio Reglamento de Bienes, en su artículo 58,2, sólo concede a sus previsiones, en este particular, un valor subsidiario en relación con el Reglamento de Servicios".

Por otra parte, el que se utilice el procedimiento licitatorio para otorgar este tipo de autorizaciones constitutivas a que se refiere el artículo 61,2 del Reglamento de Bienes no desvirtúa su naturaleza de acto administrativo unilateral; lo verdaderamente relevante en la concesión no es la forma, sino la sustancia. La convocatoria para otorgar una concesión de dominio público, al igual que ocurre con el concurso o la oposición para cubrir una plaza de funcionario en la Administración, no otorga carácter contractual a la relación jurídica que de ella surge (24).

\section{CONCLUSIONES}

Resumiendo todo lo expuesto llegamos a las siguientes conclusiones:

a) Existe un derecho del individuo, manifestación de su propia libertad, a la utilización común o concurrente de los bienes de dominio público.

b) Este derecho sólo puede ser limitado de acuerdo con el ordenamiento jurídico. En consecuencia, las licencias que se otorgan para el ejercicio de este derecho tienen un carácter reglado,

(23) Tratado de los modos de gestión de las Corporaciones locales, Madrid, 1960. página 513.

(24) E. Garcfa de Enterrfa y T. R: Fernandez, Curso de Derecho..., pág. 385, rechazan la llamada concepción sustancial del procedimiento que intenta ver en éste la simple formación gradual de la voluntad administrativa, señalando que el procedimiento administrativo no es un acto complejo, «sino más bien un complejo de actos, todos ellos instrumentales o auxiliares del acto final resolutorio o conclusivo, sin mengua de la sustantividad jurídica independiente». 
a diferencia de las autorizaciones discrecionales a que nos referimos en el apartado $c$ ).

c) La utilización de los bienes de dominio público se lleva a efecto de una manera común o concurrente y privativa o excluyente. Los denominados usos especiales - de lege ferenda- deberían quedar separados de los usos comunes y encuadrados en la figura genérica de los usos excluyentes (25), si bien sometidos a un régimen especial de precariedad, en el que el particular carece del derecho de indemnización cuando le es revocado el permiso. Por tanto, los usos privativos o excluyentes pueden otorgarse mediante actos unilaterales no constitutivos de derechos (permisos) o en régimen de concesión.

d) De lege ferenda se estima conveniente eliminar de las formas de utilización del dominio público la clasificación que distingue entre usos normales y anormales, por resultar inoperante.

e) La concesión demanial puede ser otorgada mediante acto unilateral constitutivo o mediante contrato. Como regla general se otorgará mediante acto unilateral constitutivo; sin embargo, cuando ésta se vincule a la concesión de servicios (concesiones demaniales subordinadas a la concesión de servicios), se otorgarán mediante contrato.

En esquema lo expuesto queda sintetizado así:

Usos comunes En régimen de libre concurrencia

o concurrentes En régimen de autorización reglada

Usos privativos
o excluyentes $\left\{\begin{array}{l}\text { En régimen de concesión }\left\{\begin{array}{c}\text { Otorgable por vía de acto unilateral } \\ \text { constitutivo, necesitado de acepta- } \\ \text { ción como condición de eficacia. } \\ \text { Por vía de contrato (concesión dema- } \\ \text { nial subordinada a concesión de } \\ \text { servicios). }\end{array}\right. \\ \text { En régimen de permiso (autorizaciones no constitutivas). }\end{array}\right.$

La concesión demanial, pues, se define por su contenido como instituto jurídico-administrativo en virtud del cual se transfiere a favor de personas físicas o jurídicas por la Administración, con eficacia real, duración determinada y por motivos de interés público, la utilización privativa o excluyente de una parte del dominio público.

(25) En este sentido, véase Garcta Oviedo y MartfNez Useros, pág. 408, obra citada, vol. II. 
REVL-1974, núm. 184. SANCHEZ DIAZ, JOSE LUIS. LA CONCESION EN EL REGIMEN DE UTIL...

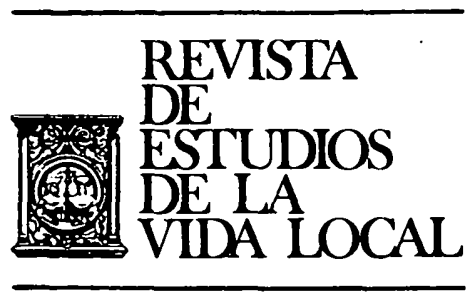

\section{CRONICAS}


REVL-1974, núm. 184. SANCHEZ DIAZ, JOSE LUIS. LA CONCESION EN EL REGIMEN DE UTIL...

REVL-1974, núm. 184. SANCHEZ DIAZ, JOSE LUIS. LA CONCESION EN EL REGIMEN DE UTIL... 